Bull. Mater. Sci., Vol. 2, Number 4, November 1980, pp. 239-249. (C) Printed in India.

\title{
Structural and dielectric studies of some niobate-titanate systems
}

\author{
A M VARAPRASAD*, A L SHASHI MOHAN**, \\ D K CHAKRABARTY and A B BISWAS $\dagger$ \\ Solid State Laboratory, Chemistry Department, Indian Institute of Technology, \\ Bombay 400 076, India \\ * Present address : Hindustan Lever Research Centre, Bombay 400 093, India \\ ** Present address : Grindwell-Norton Ltd., Bangalore 560 049, India
}

MS received 23 February 1980

\begin{abstract}
Ferroelectric ceramics of the general formula $x\left(\mathrm{Li}_{1 / 2} \mathrm{La}_{1 / 2} \mathrm{TiO}_{3}\right)(1-x)$ $\left(\mathrm{LiNbO}_{3}\right)$ have been found to have tungsten bronze (TTB) and ilmenite type structure in the ranges $0.8 \leqslant x \leqslant 1.0$ and $0 \leqslant x \leqslant 0.2$ respectively. The system is biphasic in the other ranges. All single phase materials exhibit dielectric anomalies in the temperature range $300-600 \mathrm{~K}$. The high dielectric constant of the TTB phase is explained as due to the existence of localised rotational excitons arising from a large number of defect structural units and their coupling with one of the low frequency lattice modes. Information about the lattice modes to which the rotational excitons are coupled has been obtained from Raman spectra.
\end{abstract}

Keywords. Dielectrics; ceramics; phase transitions; niobate-titanate systems.

\section{Intraduction}

Lithium lanthanum titanate $\left(\mathrm{Li}_{5} \mathrm{La}_{5} \mathrm{Ti}_{10} \mathrm{O}_{30}\right)$ and lithium niobate $\left(\mathrm{LiNbO}_{3}\right)$ exhibit several interesting properties. Both are ferroelectric, but the former crystallises in tetragonal tungsten bronze (TTB) structure and has high dielectric constant $(37,000)$ and low Curie temperature $\left(T_{\sigma}=337 \mathrm{~K}\right)$; the latter has ilmenite structure, low dielectric constant $(200)$ and high $T_{\theta}(1483 \mathrm{~K})$ (Nassu et al 1966; Varaprasad et al 1979). In our programme of developing materials for dielectric application, we felt worthwhile to study the solid solutions of these two compounds to obtain new ferroelectric materials and particularly to understand the nature of ferroelectric mode in TTB ferroelectrics where the observed dielectric behaviour is not explained by the Lyddane-Sachs-Teller (LST) and soft phonon mechanisms (Burns 1976; Reinecke and Nagi 1978; Van Kramendouk 1968).

\section{Experimental}

The compounds were prepared by three-stage heat treatment of mixtures of $\mathrm{La}_{2} \mathrm{O}_{8}, \mathrm{TiO}_{2}, \mathrm{Nb}_{2} \mathrm{O}_{5}$ and $\mathrm{Li}_{2} \mathrm{CO}_{3}$ (all $\mathrm{AR}$ grade) in required proportions in pelletised 
form at about $1275 \mathrm{~K}$ for a total period of $72 \mathrm{hr}$. X-ray diffraction patterns of the powdered samples were recorded on a diffractometor (Philips PW 1140) using $\mathrm{CuK}_{\mathrm{a}}$ radiation.

Dielectric measurements were carried out on a Wayne-Kerr B642 autobalance bridge operating at a fixed frequency $(1542 \mathrm{~Hz})$ and at a voltage $200 \mathrm{mV}$. The details of the measurement, method and specimen preparation have been reported earlier (Varaprasad et al 1979).

Infrared spectra in the region $200-1000 \mathrm{~cm}^{-1}$ were recorded as nujol mulls on a PE-577 grating spectrometer. The region $50-200 \mathrm{~cm}^{-1}$ were recorded on a Fourier transform spectrometer with a polyethylene window. Raman spectra of the powdered samples were obtained using an instrument (Jobin-Yvon make Ramanor HG2S) that uses $50 \mathrm{~mW}$ He-Ne laser $(\lambda=6328 \AA)$ as the exciting line.

\section{Results and discussion}

\subsection{Structure}

Structural data are presented in table 1. Monophasic solid solutions are obtained in the range $0 \leqslant x \leqslant 0.2$ with ilmenite structure and $0.8 \leqslant x \leqslant 1.0$ with TTB structure.

The unit cell of the TTB structure is ten formula units. A projection of this structure looking down the tetragonal c-axis is shown in figure 1. The corner shared $\mathrm{BO}_{6}$ octahedral give rise to three-fold, four-fold and five-fold cavities (designated as $\alpha, \beta$ and $\gamma$ sites respectively). The $\alpha$-sites $(0.63 \AA)$ can only be occupied by $\mathrm{Li}^{+}$(ionic radius $=0.60 \AA$ ). During the formation of solid solutions with TTB structure, substitution of $\mathrm{Li}^{+}$from $\mathrm{LiNbO}_{3}$ increases the lithium ion concentration in the $\mathrm{A}$ cation sublattice. In $\mathrm{Li}_{5} \mathrm{La}_{5} \mathrm{Ti}_{10} \mathrm{O}_{30}(x=1 \cdot 0)$ there are four $\mathrm{Li}^{+}$in the $\alpha$-sites and one in a $\beta$-site while the remaining $\mathrm{A}$ cation sites (four $\gamma$-sites and one $\beta$-site) are occupied by $\mathrm{La}^{3+}$ ions. From site preference considerations, the additional $\mathrm{Li}^{+}$ions in the solid solution are expected to enter the $\beta$-sites until all such sites are occupied. This corresponds to the composition $\mathrm{Li}_{6} \mathrm{La}_{4} \mathrm{Ti}_{8} \mathrm{Nb}_{2} \mathrm{O}_{30}$ or $x=0 \cdot 8$. A further increase in $x$ will compel the $\mathrm{Li}^{+}$ions to enter the large $\gamma$-sites that leads to the collapse of the structures. This restricts the solubility in the TTB structure to $x=0.8$.

In the $\mathrm{LiNbO}_{3}$ rich region $(x \leqslant 0 \cdot 2)$, the solid solutions have the structure similar to $\mathrm{LiNbO}_{3}$. The lithium niobate structure is based on a hep array of

Table 1. X-ray and dielectric data of the $(1-x)\left(\mathrm{LiNbO}_{3}\right): x\left(\mathrm{Li}_{1_{1},} \mathrm{La}_{1 / \mathrm{g}} \mathrm{TiO}_{3}\right)$

\begin{tabular}{llrrrr}
\hline $\begin{array}{c}\text { Composition } \\
x\end{array}$ & $\begin{array}{c}\text { Structure } \\
\text { type }\end{array}$ & $a / \AA$ & $c / \AA$ & $\begin{array}{c}\epsilon \text { at } \\
300 \mathrm{~K}\end{array}$ & $\begin{array}{c}\text { tan } \delta \text { at } \\
300 \mathrm{~K}\end{array}$ \\
\hline & & & & & \\
0.0 & Ilmenite & $5 \cdot 150$ & $13 \cdot 816$ & $32 \cdot 0$ & $0 \cdot 090$ \\
$0 \cdot 2$ & Ilmenite & $5 \cdot 123$ & $13 \cdot 723$ & $42 \cdot 3$ & $0 \cdot 040$ \\
$0 \cdot 8$ & TTB & $12 \cdot 047$ & $3 \cdot 874$ & $581 \cdot 2$ & $0 \cdot 706$ \\
$0 \cdot 95$ & TTB & $12 \cdot 056$ & $3 \cdot 864$ & 30000 & $0 \cdot 725$ \\
$1 \cdot 0$ & TTB & $12 \cdot 160$ & $3 \cdot 860$ & 21400 & $0 \cdot 162$ \\
\hline
\end{tabular}




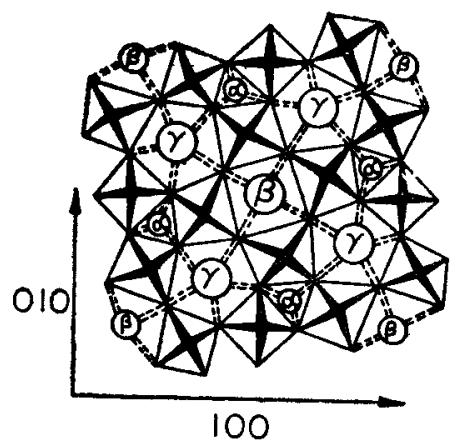

Figure 1. Projection of the tungsten bronze type structure looking down the tetragonal $c$-axis. The dark crosses represent the $\mathrm{BO}_{6}$ octahedra with $\mathrm{B}$ ions at the centres and $O$ ions at the corners. The $A$ cations are in a plane $c / 2$ above the B ions.

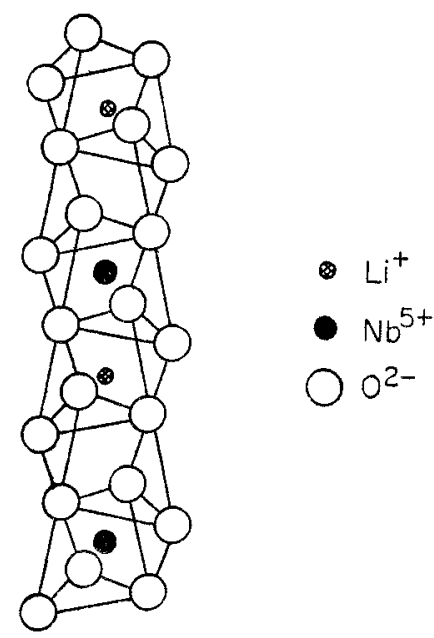

Figure 2. Structure of $\mathrm{LiNbO}_{3}$.

oxide ions. This gives rise to octahedra with centres on the triad axes and shared faces perpendicular to the axes (figure 2). Two successive octahedral positions will be occupied by $B$ and $A$, third empty and this sequence will repeat. In the ilmenite phases, it is expected that the addition of small amounts of $\mathrm{La}^{3+}\left(r_{L_{a}++}=\right.$ $1 \cdot 46 \AA)$ at the $\mathrm{Li}^{+}$site will create a large distortion thus restrictitng the solubility.

\subsection{Tungsten bronze phases}

3.2a. Dielectric properties: Variation of dielectric constant $(\epsilon)$ and $\tan \delta$ with temperature for the TTB phases are shown in figure 3 and the data are presented in table 1. The Curie temperature $\left(T_{0}\right)$ for $\mathrm{Li}_{5} \mathrm{La}_{5} \mathrm{Ti}_{10} \mathrm{O}_{30}$ is $337 \mathrm{~K}$ (Varaprasad et al 1979). The solid solutions $(x=0.8-0.95)$ show distinct dielectric anomalies. We could not, however, obtain the peak positions as our exprimental set-up 


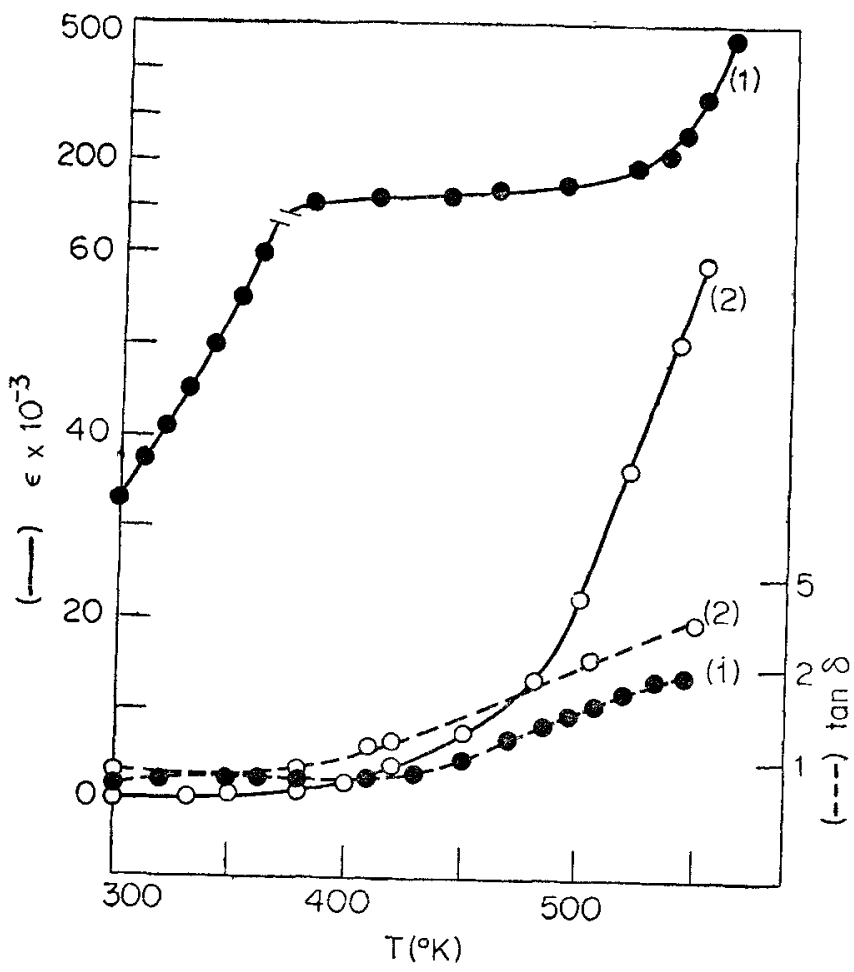

Figure 3. a. Dielectric constant $(\epsilon)$ and b. $\tan \delta$ versus temperature for the TTB phase in the system $x\left(\mathrm{Li}_{1 / 2} \mathrm{La}_{1 / 2} \mathrm{TiO}_{8}\right)(1-x) \mathrm{LiNbO}_{3 *}$ (1) $x=0.95$ and (2) 0.80 . NB : Note the change of $\epsilon$ scale at $\sim 60 \times 10^{-3}$.

could not measure $\epsilon$ beyond $550 \mathrm{~K}$. The shape of the curves suggest that these compositions may be ferroelectric with $T_{c}$ lying at a higher temperature. The $\tan \delta$ values increase gradually with temperature.

(i) Ferroelectric mode: Unlike the simple displacive ferroelectrics such as $\mathrm{BaTiO}_{3}$, the soft mode in TTB phases is temperature-independent and such materials did not conform to the soft phonon behaviour. Also, the dielectric constants are about two orders higher than what is deduced from the simple L.S.T. relation (Lyddane et al 1941). To explain this behaviour, Burns (1976) has proposed a model based on the coupling of one of the low frequency modes with impurity oscillators associated with the structural distortions of the TTB lattice. The observed large $\epsilon$ values, however, will need a concentration of impurity oscillators as large as $10^{22}-10^{23}$. In the TTB structure, each of the small units $(\alpha, \beta$ or $\gamma)$ is different from its neighbours and may be treated as impurity. We identify these impurity oscillators with the localised rotational excitons (rotons) as observed in the case of solid ortho hydrogen (Van Kramendouk 1968). These can be dynamic and unstable in the ferroelectric state due to the possibility of existence of competing phases with nearly equal energy as evidenced by the occurrence of several phases in isostructural compounds. For example, a rotation of the $\mathrm{BO}_{6}$ octahedra that are linked to the $\beta$-site $\mathrm{A}$ cation at the centre of 
TTB unit cell (represented by dotted square in figure $4 \mathrm{~b}$ ) will transform it into ten equivalent perovskite unit cells (figure 4a). An excitation between two such local levels is possible through its coupling with low frequency transverse optic mode-say an $\mathrm{AB}-\mathrm{O}_{3}$ mixed mode or a simple lattice mode $\mathrm{A}-\mathrm{BO}_{3}$. In either case, it is the coupling of the rotational motion of the group of $\mathrm{BO}_{6}$ octahedra with their vibration against $\mathrm{A}$ cations, i.e. rotation-vibration coupling. Evidence of such rotation-vibration coupling is obtained from Raman spectra and will be discussed in $\S 3.2 b$.

The generalised expression of Burns (1976) should apply to TTB materials at any temperature whenever the concentration of impurity rotons is high enough. If a sufficiently large number of rotons can be excited in these materials, this may lead to large values of $\epsilon$ at temperatures quite away from $T_{c}$.

(ii) Curie temperature : Attempts to relate $T_{c}$ of the TTB phases to the ratio of the lattice parameters did not meet with success (Geiss et al 1969). Curie temperature and possible $\beta$-site ions of some TTB phases are compled in table 2 . It can be seen that the large trivalent $\mathrm{La}^{3+}$ ion in $\beta$-site lowers $T_{c}$ and small monovalent ion raises it. The presence of large $\mathrm{La}^{3+}$ ions in the $\beta$-sites makes it difficult to achieve the bonding rearrangements involved in going from TTB to perovskite structure. The large ion will also give rise to greater geometrical friction. These factors reduce the vibration-rotation coupling and hence decreases $T_{\boldsymbol{c}}$.

3.2b. Lattice dynamics: The infrared and Raman spectra of the compounds are presented in figures 5 and 6 respectively. There is a basic similarity of these spectra with that of $\mathrm{BaTiO}_{3}$ suggesting that the lattice dynamics of the TTB and perovskite phases are similar. Of the 144 normal modes of vibration arising from the 50 atoms, all are not expected to show up. The observed spectra were interpreted by several authors (Pinezuk et al 1969; Verble and Liu 1975; Ross 1970; Burns et al 1969; Burns 1970) in terms of the internal modes of the $\mathrm{BO}_{6}$ octahedra and lattice modes of the A-type cations against the $\mathrm{BO}_{6}$ octahedra as in the case of a simple perovskite. The $\mathrm{BO}_{6}$ octahedron has five triply degenerate normal modes $4 F_{1 u}+F_{2 u}$. Three of the $F_{1 u}$ modes are IR active and the

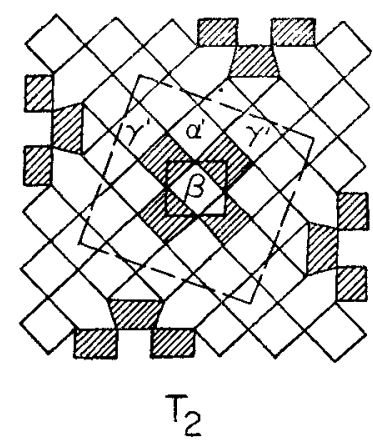

(a)

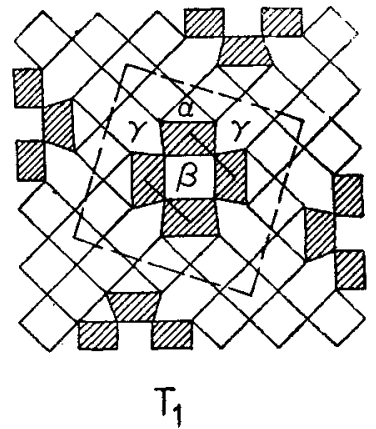

(b)

Figure 4. a. Configuration of the TTB lattice under rotational excitation. b. An extended TTB lattice. Dotted square represents the unit cell.

The small square at the centre shows the geometrical rotation involved in going from (b) to (a). Ferroelectrics, 20309.

NB : Adapted from Reinecke TL and Nagi $K$ L 1978 
Table 2. Curie temperature $\left(T_{0}\right)$ and probable $\beta$-site ion in some TTB materials.

\begin{tabular}{lll}
\hline Composition & $T_{0}\left({ }^{\circ} \mathrm{C}\right)$ & $\begin{array}{l}\text { Probable } \\
\mu \text {-site ion }\end{array}$ \\
\hline
\end{tabular}

\begin{tabular}{|c|c|c|c|}
\hline $\mathrm{La}_{2} \mathrm{~K}_{4} \mathrm{Nb}_{10} \mathrm{O}_{30}$ & -120 & $\mathbf{L a}$ & Ainger et al (1972) \\
\hline $\mathrm{Ba}_{3} \mathrm{La}_{3} \mathrm{Ti}_{5} \mathrm{Nb}_{5} \mathrm{O}_{30}$ & -130 & $\mathrm{La}$ & Ikeda and Haraguchi (1970) (Ikeda et al (1971) \\
\hline $\mathrm{Ba}_{4} \mathrm{La}_{2} \mathrm{Ti}_{4} \mathrm{Nb}_{6} \mathrm{O}_{30}$ & -80 & $\mathrm{La}$ & $\begin{array}{l}\text { Ikeda and Haraguchi (1970), Ikeda et al } \\
\text { (1971) }\end{array}$ \\
\hline $\mathrm{Ba}_{5} \mathrm{LaTi}_{3} \mathrm{Nb}_{7} \mathrm{O}_{30}$ & -55 & $\mathrm{La}, \mathrm{Ba}$ & $\begin{array}{l}\text { Ikeda and Haraguchi (1970), Ikeda et al } \\
\text { (1971) }\end{array}$ \\
\hline $\mathrm{Na}_{2} \mathrm{Sr}_{4} \mathrm{Nb}_{10} \mathrm{O}_{30}$ & +270 & $\mathrm{Na}$ & $\begin{array}{l}\text { Wemple et al (1968) and van Uitert et al } \\
(1967,1968)\end{array}$ \\
\hline $\mathrm{LiKSr}_{4} \mathrm{Nb}_{10} \mathrm{O}_{30}$ & +145 & $\mathrm{Li}, \mathrm{Sr}$ & $\begin{array}{l}\text { Watanabe et al (1970) and Kitahiro et al } \\
(1969)\end{array}$ \\
\hline $\mathrm{LiNaSr}_{4} \mathrm{Nb}_{10} \mathrm{O}_{30}$ & +260 & $\mathrm{Li}, \mathrm{Na}$ & Watanabe et al (1970) \\
\hline $\mathrm{Na}_{2} \mathrm{Ba}_{4} \mathrm{Nb}_{10} \mathrm{O}_{30}$ & +560 & $\mathrm{Na}$ & $\begin{array}{l}\text { Wemple et al (1968) and van Uitert et al } \\
(1967,1968)\end{array}$ \\
\hline $\mathrm{Li}_{2} \mathrm{Ba}_{4} \mathrm{Nb}_{10} \mathrm{O}_{30}$ & +586 & & Hirano et al (1970) \\
\hline $\mathrm{Li}_{5} \mathrm{La}_{5} \mathrm{Ti}_{10} \mathrm{O}_{30}$ & +64 & $\mathrm{Li}, \mathrm{La}$ & Varaprasad et al (1979) \\
\hline $\mathrm{Li}_{6} \mathrm{La}_{4} \mathrm{Ti}_{8} \mathrm{Nb}_{2} \mathrm{O}_{30}$ & $>+275$ & $\mathrm{Li}$ & Present work \\
\hline
\end{tabular}

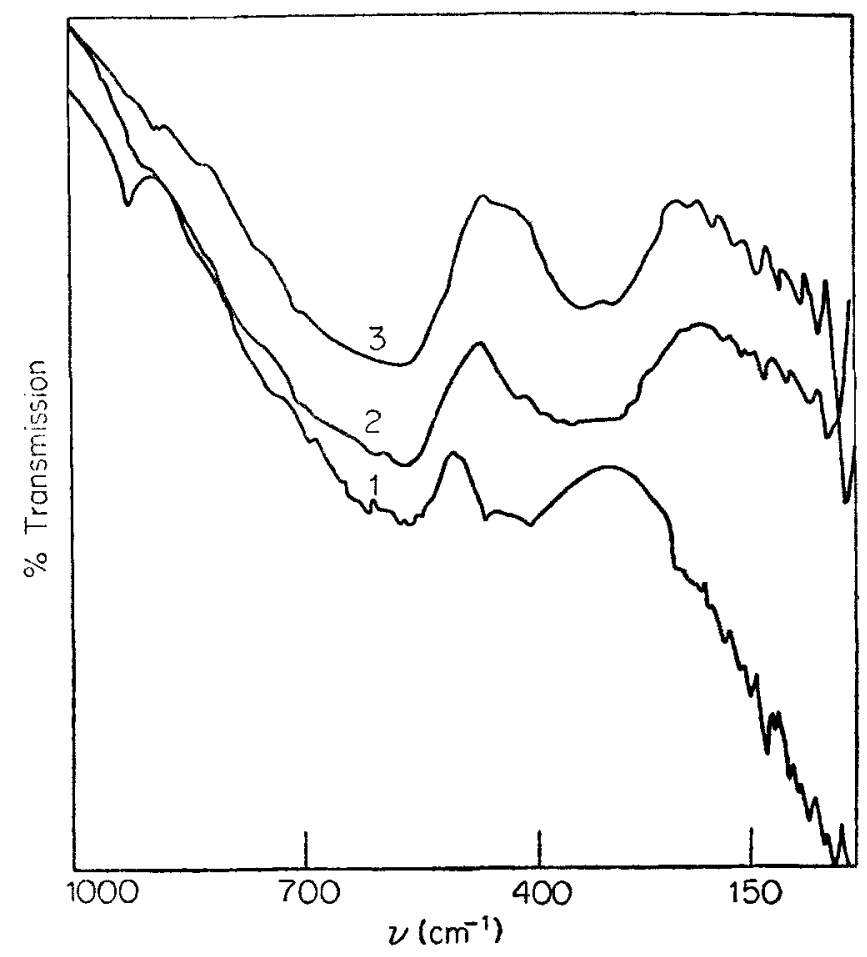

Figure 5. IR spectrum of TTB phases in the system $x\left(\mathrm{Li}_{1 / 2} \mathrm{La}_{1 / 2} \mathrm{TiO}_{3}\right):(1-x)$ $\left(\mathrm{LiNbO}_{8}\right.$ ). (1) $x=1.00$, (2) 0.95 and (3) 0.80 . Range $50-200 \mathrm{~cm}^{-1}$ taken on a Fourier transform IR spectrophotometer. 


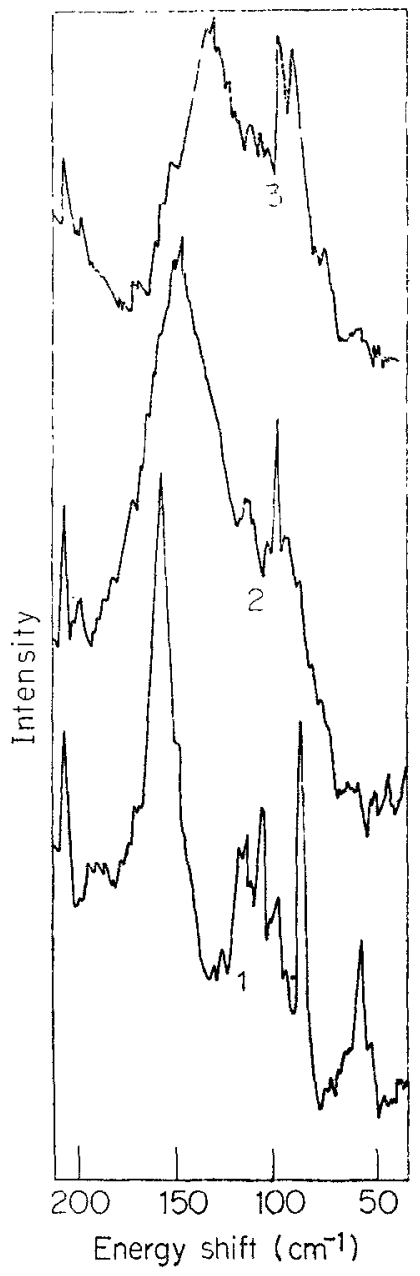

Figure 6. Raman spectrum of TTB phases in the system $x\left(\mathrm{Li}_{1,2} \mathrm{La}_{1,2} \mathrm{TiO}_{2}\right):(1-x)$ $\left(\mathrm{LiNbO}_{3}\right.$ ). (1) $x=1.00$, (2) 0.95 and (3) 0.80 .

fourth one is the translational mode. $F_{2 u}$ mode is IR inactive. The IR spectra thus showed three broad bands : (i) B-O stretching near $600 \mathrm{~cm}^{-1}$, (ii) B-O bending near $400 \mathrm{~cm}^{-1}$, (iii) $\mathrm{A}-\mathrm{BO}_{6}$ lattice modes appearing between $1-200 \mathrm{~cm}^{-1}$. The symmetry of the $\mathrm{BO}_{6}$ group in the TTB ferroelectric phases is $C_{4 v}$ and each of the $F_{1_{u}}$ modes will transform into $\mathrm{E}$ and $\mathrm{A}$ modes. Also, owing to the noncentrosymmetric nature of $C_{4 v}$ point group, the modes will be both IR and Raman active.

The observed spectra are thus classified into three groups due to (i) B-O stretching $\left(v_{1}\right)$, (ii) $\mathrm{B}-\mathrm{O}$ bending $\left(v_{2}\right)$ and (iii) $\mathrm{A}-\mathrm{BO}_{3}$ lattice modes $\left(<200 \mathrm{~cm}^{-1}\right)$ and are presented in table 3 . The IR bands are generally broader than the Raman bands and in the lattice mode region, the IR spectra ane more or less continuous due to the overlapping of the broader bands while the Raman spectra show discrete sharp bands very near the exciting line. Branching of $v_{1}$ and $v_{2}$ are 


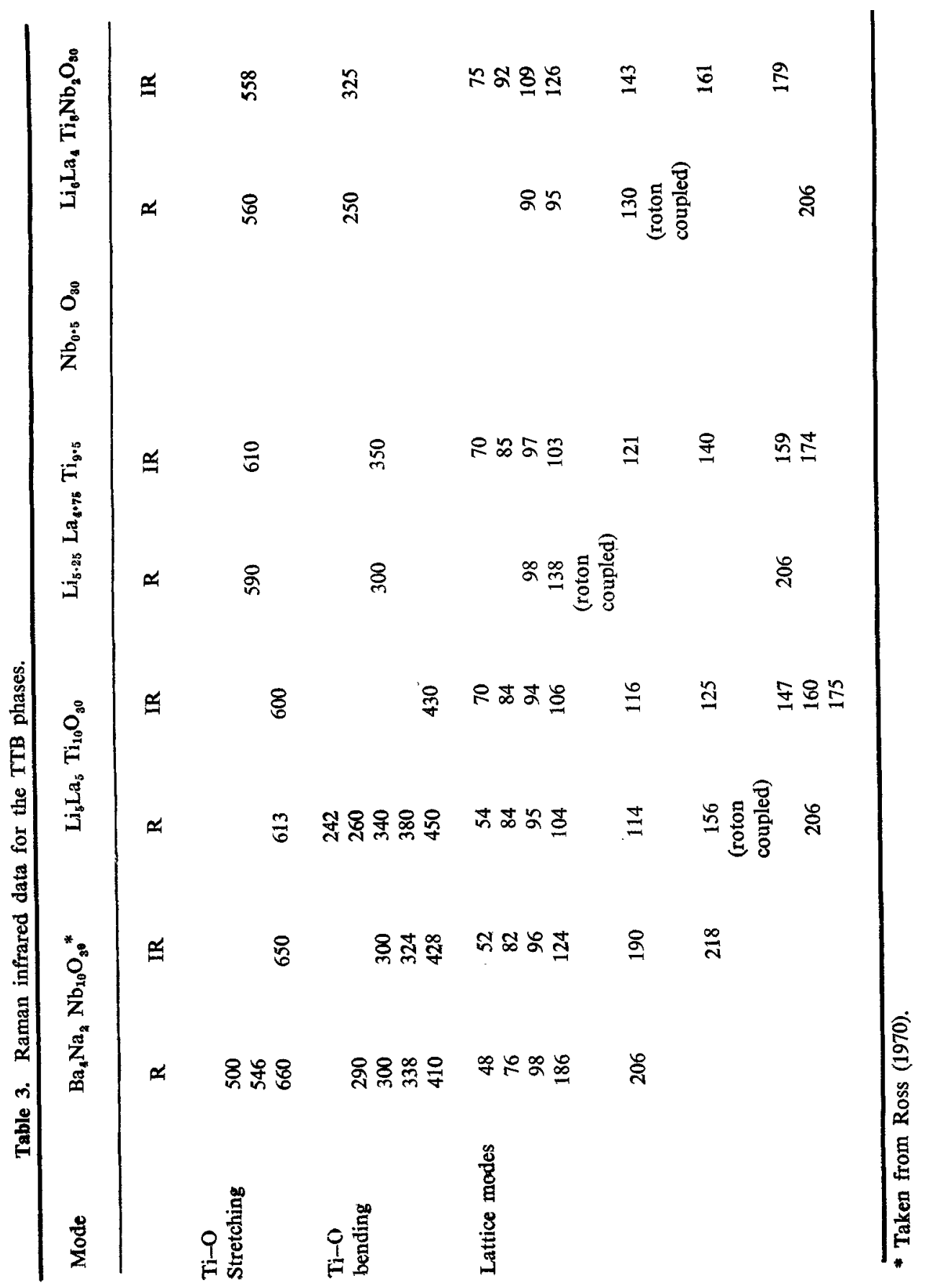


observed in certain cases (splitting of $F_{1_{w}}$ to $A_{1}+E$ ). The IR spectra of these two modes also show a split structure due to the influence of the $A$ cations surrounding the $\mathrm{BO}_{6}$ octahedra. The splitting is appreciably large in case of $\mathrm{Li}_{8} \mathrm{La}_{5} \mathrm{Ti}_{10} \mathrm{O}_{30}$ but decreases by increasing the concentration of $\mathrm{Li}^{+}$.

(i) Lattice modes : Due to the presence of different small units $(\alpha, \beta$ and $\gamma$ types) containing $A$ cations linked to the $\mathrm{BO}_{6}$ octahedra, quite a few lattic: modes are expected. The Raman spectra of the TTB phases show a number of distinct and well-separated bands. An analysis of the lattice modes was done by Ross (1970) for $\mathrm{Ba}_{4} \mathrm{Na}_{2} \mathrm{Nb}_{10} \mathrm{O}_{30}$ based on Born-Van Karman theory (Born and Van Karman 1912, 1913) and the data are included in table 3 for comparison.

It can be seen from figure 6 that the Raman cross-section of the lattice modes is small $\left(2-10 \mathrm{~cm}^{-1}\right)$ except the $\sim 130 \mathrm{~cm}^{-1}$ mode. The observed cross-section of this mode is 15,35 and $40 \mathrm{~cm}^{-1}$ for compositions $x=1.0,0.95$ and 0.80 respectively. Increase in the Raman cross-section is expected whon they are coupled with roton modes (Hardy et al 1969). By analogy, we identify the $\sim 130 \mathrm{~cm}^{-1}$ mode as the one coupled with localised rotons as described in $\S 3.2 \mathrm{a}$. The observed increase in cross-section with decreasing $x$ supports the conclusion that the vibration-rotation coupling increases with $\mathrm{Li}^{+}$concentration at the $\beta$-sites.

The IR bands arising from various lattice modes are not separated due to overlapping of the bands. However, a few equally spaced $\left(\sim 16 \mathrm{~cm}^{-1}\right)$ bands are shown in certain spectra. The $16 \mathrm{~cm}^{-1}$ spacing is significantly large and the four-fold symmetry of the rotating $\beta$-type sub-unit suggests that each of the fine structure line may be a multiplet consisting of one strong and three weak lines (Banwell 1978). In the absence of such resolution, it is difficult to identify the lattice mode coupled with rotons from IR spectra.

\subsection{Ilmenite type phases}

Dielectric properties of the $\mathrm{LiNbO}_{3}$-type phases $(x=0$ and $0 \cdot 2)$ are shown in figure 7 and structural data are presented in table 1 . The observed values of $\epsilon$

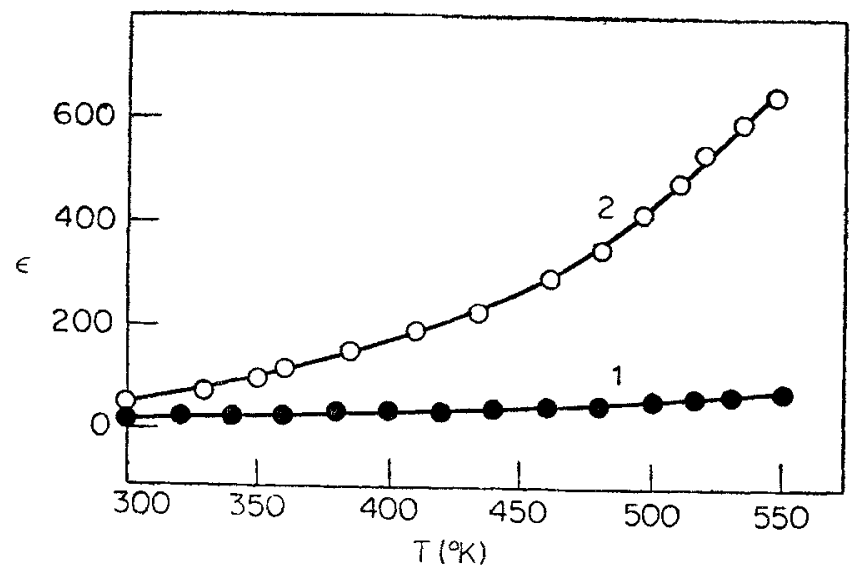

Figure 7. Dielectric constant $(\epsilon)$ versus temperature for the $\mathrm{LiNbO}_{3}$ type phases in the system $x\left(\mathrm{Li}_{1 / 2} \mathrm{La}_{1 / 2} \mathrm{TiO}_{3}\right):(1-x) \mathrm{LiNbO}$ (1) $x=0$ and (2) $0 \cdot 2$. 
(figure 7) for $\mathrm{LiNbO}_{3}$ compare very well with data reported by Nassu et al (1966). The inorease in dielectric constant for $x=0.2$ is possibly due to the substitution of $\mathrm{Li}^{+}$by the highly polarisable $\mathrm{La}^{3+}$ in $\mathrm{LiNbO}_{3}$ structure. The $\tan \delta$ values are small $(\sim 0.05)$ and are practically temperature- independent.

The far IR spectra of these compositions are presented in figure 8 . The spectrum of $\mathrm{LiNbO}_{3}$ agrees with the single crystal spectrum reported by Barker (1966). Temperature dependence of the lattice modes have been studied by Barker (1966) and Barker and Loudon (1967) which revealed that the $248 \mathrm{~cm}^{-1}$ mode is relatively the softest and is responsible for ferroelectric transition. The band intensity is redued considerably for $x=0.2$ probably due to the reduction in the atomic displacements (order parameter) involved at its Curie temperature.

\section{Conclusions}

The addition of $\mathrm{LiNbO}_{3}$ to $\left(\mathrm{Li}_{1 / 2} \mathrm{La}_{1 / 2}\right) \mathrm{TiO}_{3}$ has given rise to monophasic TTB type solid solutions upto a $\mathrm{Li}^{+}$concentration 0.6 (i.e. $x \leqslant 0.8$ ). Solubility is restricted by the fact that further addition of $\mathrm{Li}^{+}$will force it to enter the large $\gamma$-sites thus making the structure unstable. The addition of $\mathrm{LiNbO}_{3}$ leads to increased dielectric constant and $T_{c}$. Such an improvement in the dielectric properties is due to the substitution of $\mathrm{La}^{3+}$ by $\mathrm{Li}^{+}$in the $\beta$-sites that facilitates the exchange process between the various dynamic configurations. This increases the degree of coupling between the lattice modes and the localised rotons thus increasing $\epsilon$ and $T_{0}$.

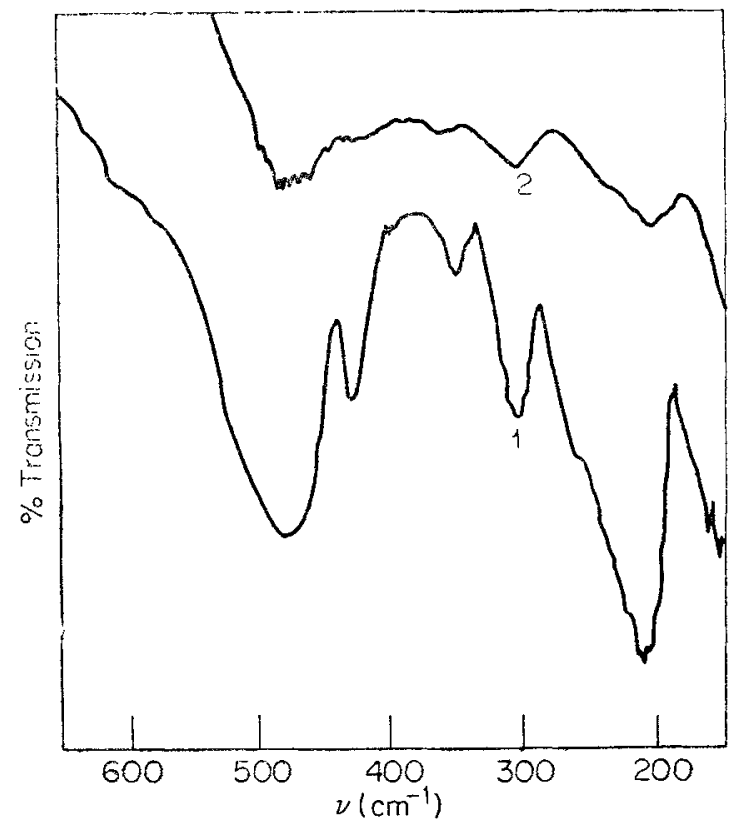

Figure 8. IR spectrum of the $\mathrm{LiNbO}_{3}$ type phases in the system $x\left(\mathrm{Li}_{1 / 2} \mathrm{La}_{1 / 2} \mathrm{TiO}_{3}\right)$ : $(1-x) \mathrm{LiNbO}_{8}$ (1) $x=0$ and (2) $0 \cdot 2$. Range $\left(150\right.$ to $\left.650 \mathrm{~cm}^{-1}\right)$ taken on a Fourier transform IR spectrophotomer. 
Compositions $0 \leqslant x \leqslant 0 \cdot 2$ retain the $\mathrm{LiNbO}_{3}$ structure. The far IR spectra and dielectric behaviour of these compositions are similar to that of $\mathrm{LiNbO}_{3}$.

\section{Acknowledgements}

We are grateful to Prof. S Mahapatri, Dr T K K Srinivasan, Prof. G Tyagarajan for providing us some of the experimental facilities during the course of this work.

\section{References}

Ainger F W, Beswick J A, Porter S G and Clarke R 1972 Ferroelectrics 3321

Banwell C N 1978 Fundamentals of molecular spectroscopy (New Delhi: Tata McGraw-Hill) p. 103

Barker A S Jr. 1966 Proc. Symp. Ferroelectricity (Michigan: Elsevier) p. 213

Barker A S Jr. and Loudon R 1967 Phys. Rev. 158433

Born M and Van Karman T 1912 Z. Phys. 13297

Born $M$ and Van Karman T 1913 Z. Phys. 1415

Burns G 1970 J. Phys. Soc. Jpn. Suppl. 28153

Burns G 1976 Phys. Rev. B13 215

Burns G, Axe J D, and O'Kane D F 1969 Solid State Commun. 7933

Geiss E A, Scott B A, Burns G, O'Kane D F and Segmuller A J $1969 \mathrm{~J}$. Am. Ceram. Soc. 52276

Hardy W N, Issac C F S and Mc Tague J P 1969 Phys. Rev. Lett. 22297

Hirano H, Takei $\mathrm{H}$ and Koida S $1970 \mathrm{~J}$. Appl. Phys. 9580

Ikeda T and Haraguchi T $1970 \mathrm{Jpn}$. J. Appl. Phys. 9422

Ikeda T, Haraguchi T, Onedera Y and Saito T 1971 Jpn. J. Appl. Phys. 10987

Kitahiro I, Yano T and Watanabe A 1969 Jpn. J. Appl. Phys. 8807

Lyddane R H, Sachs R G and Teller E 1941 Phys. Rev. 59673

Moller K D and Rothschild W G 1971 Far infrared spectroscopy (New York : John Wiley) p. 567

Nassu K, Levinstein H J and Loiaceno G M 1966 J. Phys. Chem. Solids 27989

Pinezuk A, Burstein E and Ushidas 1969 Solid State Commun. 7139

Reinecke J L and Nagi K L 1978 Ferroelectrics 20309

Ross S D 1970 J. Phys. C3 1785

Van Kramendouk J 1968 in Proc. 1st Int. Conf. Localised Excitations in Solids ed. R F Wallis (New York: Plenum Press) p. 713

van Uitert L G, Rubin J J, Grodkievwiez W H and Bonner W A 1967 Mater. Res. Bull. 463

van Uitert L G, Levinstein N J, Rubin J J, Capico C D, Dearborn E F and Bonner W A 1968 Mater. Res. Bull. 347

Varaprasad A M, Shashi Mohan A L, Chakrabarty D K and Biswas A B 1979 J. Phys. C12 465

Verble J L and Liu S T 1975 Proc. 3rd Int. Conf. Light Scattering in Solids, Brazil eds. M Balkanski, R C C Leite and S P S Porto (Paris : Flammaion Sciences) p. 900

Watanabe A, Sato Y, Yano T and Kitahiro I 1970 J. Phys. Soc. Jpn. 28 Suppl. 93

Wemple S H, Didomenico M and Camlibel I 1968 Appl. Phys. Lett. 12209 